\title{
Nidnces of harm
}

Joumal for the Theory of Social Behaniour 32.1

$002 \mathrm{l}-8308$

\section{Electroconvulsive Therapy and the Fear of Deviance}

\section{JAMES GILES}

\section{THE BACKGROUND TO ELEGTROCONVULSIVE THERAPY}

In the 1934 the Hungarian physician Meduna attempted to cure schizophrenia with a drug which induced convulsions or seizures. The term "schizophrenia" is used to refer to either an acute or a chronic psychological condition which can take various forms. It is often characterized, however, as a persisting condition in which thinking processes are disrupted or might seem bizarre, in which hallucinations, delusions, and an altered sense of self are experienced, work and social relationships break down, self-care and personal hygiene tend to be neglected, and the person seems less and less interested in maintaining himself or herself in a way in which others feel appropriate. In some cases the person in this condition can experience fits of laughter for what are deemed to be inappropriate reasons or even for no apparent reason. In other cases the person can show catatonic behaviour, that is, behaviour in which the person assumes a peculiar position, for no apparent reason, and remains in that position for hours or even days on end (Auerbach and Blatt, 1997; American Psychiatric Association, 1994).

Why did Meduna think that causing convulsions in such persons could cure them? Meduna justified his treatment by claiming that since epileptic convulsions tend not to occur with persons with schizophrenia, such convulsions must act as a protection against schizophrenia (Meduna, 1937; 1985). That is, Meduna thought that epileptic-like convulsions and schizophrenia were biologically antagonistic. The problem, however, was that Meduna was wrong: epileptic convulsions can easily occur with schizophrenia and thus offer no protection against schizophrenia (Rudorfer and Goodwin, 1993).

Despite the falsity of Meduna's argument, in 1937 Cerletti and Bini, two Italian physicians, pursued Meduna's ideas by passing an electric current through the brain of the schizophrenic person in order to produce convulsions (Cerletti and Bini, 1938). It is worth noting that Cerletti and Bini's first subject was a vagrant who spoke "incomprehensible gibberish" and who was unable to give 
his name or any other information about himself (Impasato, 1960). The idea of using electricity as a curing agent was not, however, a new one, especially not in Italy. Roman physicians from the days of the Roman Empire were reported to have used shocks from electric cels as cures for various sorts of ailments. Later, during the 18th century when people were able to harness electromagnetic energies, there was much fascination with these phenomena. Such phenomena were seen as a mysterious forces of nature which people could direct and use creatively. The view of electromagnetism as semi-magical force was probably best exemplified in the work of the German physician Mesmer. Mesmer was convinced that magnetism controlled the movements of an invisible fluid within the body and that the blockage of this fluid was responsible for disease. Through elaborate and mysterious techniques which, interestingly, often ended with the patient undergoing delirium and convulsions, Mesmer sought to remove the blockages and reestablish the proper magnetic flow. Also, in England in 1756 Wesley, the founder of Methodism, developed an apparatus that could deliver electric shocks. He used this on "nervous Cases of every Kind" and referred to "how much Sickness and Pain may be prevented or removed, and how many Lives saved by this unparallel'd Remedy", though, it is interesting to note, at the same time complaining, "And yet with what Vehemence has it been opposed? Sometimes by treating it with Contempt, as if it were of little or no Use: Sometimes by Arguments, such as they were; and sometimes by Cautions against it's [sic] Effects, as made thousands afraid to meddle with it" (Wesley, 1760, pp. 421-422). Also, in $1787 \mathrm{St}$ Clare is reported to have cured an sepidemic of hysterics" with a portable electrical machine which dispensed shocks (Gentleman's Magazine, 1787). Likewise, in the 1850 s the French physician Baillarger tried to use electricity to cure hallucinations: "It was found, however, to be exceedingly painful and difficult in application, and was therefore abandoned" (Brierre de Boismont, 1859, p. 1060).

Because of this ancient pedigree in the use of electricity as a supposed curing agent it might seem that Cerletti and Bini had some justification for its use against schizophrenia. However, many modern day advocates of electroconvulsive therapy (ECT), as it has come to be called, feel that the supposed beneficial effects of ECT have nothing to do with the use of electricity per se, but rather with the occurrence of a grand-mal seizure (though there is no agreement why such a seizure should be beneficial). It is just that an electrical shock applied to the brain is an effective way of inducing grand-mal seizures. Since it is clear that most of the electrical shocks delivered as a cure in earlier times were not applied to the brain nor of the intensity to induce grand-mat seizures, the reported curative value of such shocks, at least when used against psychological problems, must remain highly suspect, at least to those who see the seizure itself as being instrumental.

Despite the lack of any rigorous studies or sound evidence for its effectiveness, Cerletti and Bini's new treatment for schizophrenia was avidly embraced and 
only a year later was in wide use in Western medical establishments, not only for schizophrenia, but also for various other psychological problems. Some years later the use of ECT spread further and became a common form of treatment in many of the hospitals of non-Western countries. In China, for example, ECT was in use by the end of the $1940 \mathrm{~s}$ in the then existing psychiatric facilities. As more psychiatric hospitals were built in the 1950 s, ECT became widespread throughout China ( $\mathrm{He}$ and $\mathrm{Li}, 1985$ ).

\section{THE SIDE-EFFECTS AND THEORY OF ECT}

This enthusiastic use of ECT without adequate research into its effectiveness was rendered even more peculiar by two other factors. First, numerous and sometimes serious side-effects were associated with this new treatment and, secondly, there was no clear theoretical explanation of how ECT purportedly worked or why it should be effective, especially since the initial reasoning behind its use was quickly seen to be flawed. The side-effects of ECT included both temporary and permanent intellectual impairment, anxiety, nightmares, nausea, intense headaches, speech defects, apathy, fatigue, lethargy, fractured teeth and bones, raised blood pressure, breakdown of the blood-brain barrier, possible brain damage, cardiac arrhythmia, and even death through heart attack and other complications. The intellectual impairment caused by ECT can take the form of loss of both memory acquired prior to ECT (retrograde amnesia) and memory acquired after ECT (anterograde amnesia), confabulation (inventing memories), impaired concentration and attention, impaired perception and visual-motor skills, heavily slowed reaction time, and difficulty in making abstractions and complex discriminations (Small, et al., 1986). There is also evidence that ECT damages general intelligence and vocabulary or word-finding ability (Lawson at al., 1990).

One would think in the presence of such problems that ECT, like bloodletting, would have eventually been given up. This, however, is far from the case: ECT still has strong advocates in the psychiatric profession today. By the 1990 s about 100,000 people a year in the USA alone and over double that number in the UK were still receiving ECT (Julien, 1992; Squire, 1987). Although the use of ECT in Western countries tended to decline in the $1970 \mathrm{~s}$, it is now on the increase (Feldman, 1997). For example, in 1994 10,000 ECT treatments were given in Ontario, Canada, whereas in 1998 13,000 were given. This 30 per cent increase is also true for the same period in British Columbia, Canada (Wells, 1999). The situation in non-Western countries is difficult to assess because of the lack of statistics. However, the information available indicates that, in developing countries like India and Nigeria, the percentage of psychiatric patients receiving ECT has, for several years, been even higher than those in Western countries (Odejide, 1980; Ihezue and Ebigbo, 1981; Shukla, 1981; Saju and Jacob, 1993), that while ECT use was on the decline in the West it was on the increase in

The Fxecutive Management Gommitted Blackwell Publishers Ldd. 2002 
India (Vahia $e t$ al., 1974), and that this trend is probably also continuing (see, for example, Saju and Jacob, 1993). It is this growing use of ECT, a treatment whose credentials are highly questionable, that indicates the need for continuing the debate on its use and especially for raising the issue of the motivation behind its use.

It is unclear exactly why this increased use of ECT is under way, and various explanations have been offered. Stephens et al. (1993), for example, suggest the renewed interest in ECT is probably attributable to a growing dissatisfaction with the limitations of psychopharmacology. This, however, seems implausible when one considers that the history of ECT itself, in contrast to the history of psychopharmacology, is the history of a treatment which is becoming more and more limited according to the types of psychological problems against which it is used. Once used for numerous types of psychological problems, it is now, in Western countries at least, mainly used for a few specific problems (though its use in these areas is growing). Squire (1987), claiming that ECT is cheaper than other treatments, suggests cost effectiveness might be one of the things behind ECT's increased popularity, but Fink (1993) claims that, with the required treatment team of psychiatrist, anaesthetist, nurses, and special treatment facilities, it is an expensive treatment. None of these explanations seems to be decisive. In what follows I shall be suggesting a more psychologically and culturally based explanation behind the attractions of ECT. It may well be that, with the current minimal opposition to ECT - public reaction against ECT seemed to peak in the 1970s and thereafter slowly subsided, possibly because of the subsequent decline in ECT use (Squire, 1987)- these attractions are once again free to assert themselves.

Concerning the dangers of ECT, in Western countries (though not in developing countries) the situation has changed somewhat since ECT first appeared. The use of anaesthesia, muscle relaxants, and mouth guards, or bite blocks, have reduced the occurrence of bone and teeth fractures. But the use of drugs here has the added danger that now higher amounts of current must be used to induce the seizure. This modified ECT, as it is called, also frequently (though not always) involves applying the shock to only half the brain - unilateral rather than bilateral ECT - a procedure which is supposed by some to minimize cognitive impairment (Daniel and Crovitz, 1983). There is, however, evidence against the idea that unilateral ECT causes less impairment (Janicak et al., 1991) and much disagreement about the effectiveness of the procedure and whether or not it has any benefits over bilateral treatment (see for example Abrams, 1991; Janicak et al., 1991; Squire, 1977; d'Elia and Raotma, 1975). A fewer number of sessions tend now to be used than were in earlier times: although a person might formerly have received hundreds of treatments, the usual number tends to be between six and 12 treatments (American Psychiatric Association, 1990).

Despite these supposed safeguards, however, cognitive damage, including especially temporary and permanent memory loss of events both prior to and after 
ECT still seems to be a serious side effect of ECT. Although many ECT advocates claim that memory loss is transient or only concerns events which occur in the immediate weeks before and after ECT, there is good evidence from controlled studies that even with modified ECT persons have persistent difficulties in remembering details of their lives before ECT (Freeman et al., 1980; Squire et al., 1981; Squire and Slater, 1983; Weiner et al, 1986). Further, autobiographical investigations indicate that this loss can be much more serious than for merely the time surrounding the ECT. One former ECT recipient relates how a year and a half of her life disappeared from her memory after 12 sessions of ECT (Wells, 1999). Within this time she had moved back and forth between two cities, made new friends, started and ended a relationship, and even had a pregnancy. She only later learned of these events by being told about them. She still, however, could not remember them. Breggin (1979) also describes the cases of several people wh developed extensive memory loss due to ECT. For one such person ECT obliterated most of the experiences three years prior to treatment, with some of the memory loss extending back into childhood. In another case the leader of a former ECT recipients group became unable to work when she lost her entire professional memory after eight sessions of ECT (Squire, 1987).

Another and little-explored aspect of ECT-induced memory loss is that even in those cases where the person seems to be able to remember various events prior to ECT, the phenomenology of the memory is sometimes altered. Thus persons who have had ECT sometimes feel that the memory has a strange quality of "unreality" to it, as if they had not actually been present when it occurred: "They might have a sense of recalling through a screen or filter, almost as if they remembered a movie or a second hand description, rather than the experience itself" (Breggin, 1979, p. 25). There is also evidence for persisting anterograde memory loss and mental dysfunction (Breggin, 1979, 1997; Steif et al., 1986). In this case a person who has undergone ECT has a persisting inability to retain various memories gained after ECT. One former ECT recipient describes her frustrating awareness that since her ECT she has had much difficulty remembering appointments and different things she has been told; she has had to rely on others to remind her continually of various things she has to do (Wells, 1999). In another case, a school teacher who received ECT 25 years ago says his ability to retain memories has never been the same. Before his ECT he never had such memory problems. But ever since ECT he has had problems learning new words and remembering names. In order to remember his students names while teaching he now has to rely on a class picture with each student's name written on it (Andersen and Collignon, 2001). In both retrograde and anterograde amnesia the type of memories lost are not just memories of particular events, but also memories of how to perform activities - for example, sewing, cooking, or operating machinery - that had been learned previously. Another former ECT recipient tells how after 20 sessions of ECT she sustained a memory loss in which she not only could not recognize people who she had known for 
years, but also how her knowledge of the most elementary activities were suddenly gone. She no longer could remember how to ride a bicycle, cook, and even have a bath: the idea of performing the correct sequence of running the water, disrobing, getting in the water, turning off the water, and so forth, became extremely confusing for her and took careful planning beforehand. Although she has tried to releam her earlier skills, many of them-like writing poetry and doing artwork-are permanently gone (Andersen and Collingnon, 2001). Anguish, embarrassment, and sharne typically accompany this loss of memory. The same woman describes, for example, how people would greet her by name on the street and the fear and embarrassment she would feel when she realized she did not know who they were. Another person gives an account of the immense anguish she felt over the fact that, after ECT, she could no longer remember ber wedding day, while another tells of how she would stay home because of the shame and embarrassment she felt at meeting someone on the street who knew her but whom she could not recall (Breggin, 1979).

There are of course ECT recipients who claim to have no memory loss or make light of what memory loss they do have. The problem, however, is that it is well known that confabulation and the defence mechanism of denial are closely associated with organic brain damage (Weinstein, 1996; Bond, 1985). That is, persons who have sustained brain damage are sometimes disposed to deny that any such damage has occurred. According to Bond, "the mental mechanism of denial ... is a protection against the potentially damaging effects upon emotional integrity of recognizing the real nature, extent, and significance of brain injuries and their aftermath. It operates in most patients with varying degrees of intensity during the first one to two years after injury and tends to promote expectations of recovery that ultimately cannot be met." (1985, p. 174). Thus, if someone's memory has been impaired as a result of ECT-induced organic brain damage, it is understandable that such a person might deny any memory impairment.

It is the persisting problems in memory function, particularly anterograde amnesia, that suggest some form of brain damage is one of the results of ECT. This is an area where there has been much discussion, controversy, and inconsistent evidence. As mentioned earlier, various studies have indicated the existence of organic brain damage in persons who have had ECT (for example, Andreasen et al., 1990; Calloway et al., 1981; Weinberger, et al., 1979. See also Friedberg's (1977) review). These studies indicate the occurrence of lesions, neural loss, and enlargement of sections of the brain as a result of ECT. In a oftcited review paper, however, Devananda el al. (1994), argue that studies have failed to demonstrate conclusively that ECT results in structural changes to the brain or in neural damage. Their paper, however, is flawed in several respects.

First, although they allow that the cognitive damage caused by ECT might be indicative of brain damage, they say that such damage is "transient and reversible". They then dismiss all evidence to the contrary as coming from early 
use of intensive and unmodified ECT which, they say, is not relevant to modern clinical practice. This suggests, they say, that ECT does not cause structural brain damage. But what about evidence that non-intensive modified ECT induces long-term cognitive damage, evidence like that given above, some of which can even be found in the works cited in Devananda et al.'s reference list? Devananda et al. deal with such evidence by passing over it in silence. They similarly ignore Pettinati and Bonner's (1984) evidence for a persisting reduction in visual tracking abilities in elderly persons who have had ECT - a finding which seems highly indicative of persisting brain damage.

Secondly, they also dismiss numerous studies which found brain damage in autopsies of ECT patients. They do this primarily by the speculating that here there might have been "undiagnosed intracranial pathology before ECT" and by blaming the use of unmodified ECT. They then cite Corsellis and Meyer's (1954) study of two ECT recipients who died under ECT and claim that since no neuronal loss could be detected this suggests that ECT does not cause neuronal damage. But what Corsellis and Meyer say about the findings in one of the autopsies is "there was no appreciable loss of nerve cells but these did, however, often show a loss of polarity and varying degrees of chromatolysis" (1954, p. 376). These changes, which are signs of neuronal damage, are not mentioned by Devananda et al. With the other person's autopsy Corsellis and Meyer say that although the cornu Ammonis (a section of the hippocampus) appeared normal, "the congestion of the blood vessels was exceptionally well marked" (p. 380). Although this is not neuronal damage, it is an abnormality that Devanada et al. quietly pass over. They then refer to two further studies (Heyck, 1955; Lippmann et al., 1985) which found no brain damage in two persons who had large amounts of EGT, but fail to tell us that the person in one of these studies (Lippmann et al. 1985) had earlier sustained major brain damage due to psychosurgery (bilateral leucotony) and that other sections of her brain showed "less atrophy than expected for such an elderly person" (p. 203). Both of these facts render her brain an exceptional case and thus grossly limit any generalized conclusions that can be drawn. On top of this there is no reference at all to a study by McKegney and Panzetta (1963) which describes the case of a young man who went into permanent coma 15 minutes after only one session of modifted ECT and died two months later. Here a detailed autopsy showed evidence of post-ECT brain haemorrhage.

Thirdly, although Devananda $e t$ al. claim that computerized tomography and magnetic resonance imaging studies conducted before and after ECT show no evidence of structural brain damage, they themselves admit both that there is a paucity of definitive data from such studies and also that such techniques are unable to register lesions of less than 1-2 $\mathrm{mm}$ in diameter or subtle changes in the hippocampus region of the brain. It should be obvious, however, that lesions in neural tissue need not be more than $1 \mathrm{~mm}$ to damage neural pathways. This shortcoming is especially relevant since it is known that people who suffer from epilepsy - a condition characterized, like ECT, by seizures-are liable to have 
neural damage in the hippocampus (Corsellis and Bruton, 1983). It is also relevant because animals exposed to electroconyulsive shock once a day for only 10 days develop subtle structural changes in the hippocampus (Vaidya tet al., 1999).

Further, Coffey et al.'s (1991) study, with its disagreement betwèen two teams of raters on whether magnetic resonance imaging indicated brain damage (subcortical hyperintensity in this case) following ECT, shows the subjectivity involved in interpreting the results of such techniques and thus casts further doubt over Devananda $e t$ al's claims about what brain imaging has shown.

Finally, throughout their paper they slip back and forth between the terms "structural brain damage" and "brain damage" as if the two were identical notions. But they are not. Structural brain damage need not be the only sort of brain damage, for the brain damage caused by ECT might be one of functional rather than structural damage. In such a case, although there might be no obvious structural changes in the brain (at least at the macroscopic level], the brain simply does not function in the way it did before ECT. There could be permanent changes in the way in which the brain functions to store or retrieve information, chemical or neurotransmitter production, neurons' ability to polarize or depolarize, threshold levels, or other such things, that are simply not registered by brain scans or quantitative cell counts. Such cerebral changes are clearly damage to the brain even though they may not be classified as structural brain damage. Related to this is Devananda et al.'s comment that "there is indirect evidence that physiological processes disrupting memory consolidation, rather than irreversible structural damage to the brain, are responsible for the sometimes long-lasting spotty memory loss for events that occurs during the time immediately surrounding the ECT course" (1994, p. 966). But this does not show there is no irreversible brain damage, for ECT-induced physiological alterations which have "long lasting" adverse affects on the memory sound very much like irreversible functional brain damage. This would seem to be particularly the case with persistent anterograde amnesia (which Devananda $e t$ al. here ignore) where the responsible physiological alterations would also more than likely be "long lasting".

As for the theory behind the workings of ECT, there is still no accepted explanation as to how ECT produces its supposed therapeutic results: by 1948 as many as 50 different theories had been put forward (Gordon, 1948), with considerably more appearing since then (Sackeim, 1988). As two ECT proponents put it "the precise manner by which an induced seizure produces therapeutic change continues to elude us" (Weiner and Krystal, 1993, p. 95. For the latest theory see Madsen et al., 2000)). It is worth noting here that one view which has been advanced is that the purported therapeutic effects of ECT are simply the results of the organic brain damage which is incurred as a result of ECT: seizures, EEG or brain wave slowing, memory loss, and other forms of cognitive impairment, all of which are effects of ECT, are also typical features of organic brain damage sustained by closed head injury (Breggin, 1979, 1997. For 
a discussion of the cognitive effects of closed head injury see Brooks, 1985; van Zomeren et al., 1985). In such a situation it is understandable that someone who is struggling with the symptoms of organic brain damage would initially have immense difficulty re-oricntating himself to the features of his pre-trauma life, part of which includes his depression. This view has received support from studies which indicate a causal relationship between the lifting of depression and cognitive impairment induced by ECT (Frith et al., 1983; Calev et al., 1991).

\section{EVIDENCE FOR THE EFFECTIVENESS OF ECT}

In trying to explain why ECT, despite all these problems, continues to be used, let us start by asking what exactly is ECT and what is the purported evidence for its effectiveness. Basically, ECT is a procedure in which the person is placed on a table and then has electrodes - which are connected to generator-placed on either side of the head. An electric shock is then sent through person's brain. This jolt is typically of 140 volts, 60 Hertz, for 0.4 seconds or longer, which produces 25-40 watt-seconds or joules. Varying settings can produce between two to 130 joules per treatment. The immediate result of this shock to the brain is a grand-mal seizure defined by a definite EEG pattern in which consciousness is lost and the body is thrown into violent muscle contractions (it is here that the bone and teeth fractures can occur). The seizure induced by the current is intended to be a grand-mal seizure that can last for varying amounts of time. Some advocates feel the seizure should last for at least 25 seconds (Small, et al, 1986). Consciousness, with resultant amnesia, confusion, fear, and headaches, usually returns between five and 20 minutes afterwards. In modified ECT the person is usually under a general anaesthetic and, as mentioned, is given muscle relaxants. This means that the muscle contractions caused by the seizure are much weaker than in unmodified ECT, sometimes making the recipient show little more than a facial grimace and twitching of the feet (Squire, 1987). The person is also given oxygen to prevent possible hypoxia and cyanosis (common reactions to both the seizure and the muscle relaxants), with the electrodes usually being placed over only one half of the brain typically the non-dominant hemisphere. The amount of electricity is then adjusted to be enough to cause a grand-mal seizure which should last for the amount of time chosen by that the prescribing psychiatrist.

What then is the evidence for the effectiveness of this procedure? In the early days of ECT practitioners were enthusiastic about this new treatment and various glowing reports were issued about its effectiveness. However, when the first systematic studies of ECT started to appear (such as Langsley et al., 1959; King, 1960) it became clear that when used against schizophrenia ECT was no better than drug therapy and even that ECT recipients stayed in hospital significantly longer that those treated with drugs alone. Further studies (Naidoo, 1956; Goller,

The Executive Management Committee/Blackwell Publishers Ltd. 2002 
1960) showed that ECT offered no advantage when combined with drug therapies. Although a couple of later studies (Childers, 1964; Smith et al., 1982) found that schizophrenic patients receiving EGT in combination with drug therapy initially did better than those receiving drug therapy alone, only one of these (Smith et al., 1982) did a follow-up. Here, there was no difference between the two groups at six and twelve months. Still, one might want to argue that this shows that ECT is at least as effective as drug treatment. But even here it must be noted that, like the early positive reports, none of these findings was derived from double-blind controlled studies. We now know, however, that a doubleblind study - a study in which neither the subject nor the researcher know if the subject is in a treatment group or a control group is essential to control for both subject and researcher bias or expectation. For it has been shown that both the researcher's and the subject's expectations about the effectiveness of a treatment can easily affect the perceived outcome of the treatment, regardless of whether the treatment itself is effective or not (Harris, 1991; Blanck, 1993). Double-blind studies of the effectiveness of ECT only began to appear in the late 1970s. Here, the results seem even less convincing, with much inconsistency across different studies (Taylor and Fleminger, 1980; Small et al., 1982). These findings seemed to have convinced most workers in the field (though not all) that EGT, with all its attendant risks, is not indicated in schizophrenia. The same inconsistencies surround the research of the use of ECT with mania, a condition characterized by hyper-excitability, extreme emotional elation, and a flight of ideas. Although some people claim that ECT is effective with mania, Small et al. (1988) found that any superiority of ECT over lithium carbonate (an antidepressant) for manic patients disappeared eight weeks after treatment. In their recent review of the literature Keck et al. (2000) conclude that there is a lack of controlled evidence for claims about the effectiveness of ECT with mania.

Most ECT advocates feel that the best case for ECT is found in severe or psychotic depression. In clinical depression a person falls into a deep sadness which persists for an extended amount of time. This sadness may or may not be a response to an obvious event, say the loss of a loved one. In this condition the person loses interest or pleasure in most activities, feels worthless, can see no purpose in life, and is preoccupied with thoughts of death and suicide. This is also frequently accompanied by conditions like loss of energy and sexual interest, significant weight loss or gain, and insomnia or hypersomnia. It is, however, only when depression shows psychotic features that ECT advocates normally feel ECT is indicated. In psychotic depression many of these features become even more severe and the person begins to experience hallucinations and delusions. However, here again there are many problems in the literature concerning the effectiveness of ECT. Thus, in a review of the literature Scott (1989) concluded that many depressed persons do not respond to ECT, and that even when there is a positive response this can be followed by relapses back into depression. Some researchers, however, argue that ECT works with severe depression because, 
they say, studies have shown that ECT has better effects than a placebo or sham ECT (Barton, 1977; Janicak et al., 1987). In these studies real ECT is compared with a simulated ECT within a double-blind structure in order to control for both researcher and subject expectations. Thus while one group of subjects receives real ECT the other group goes through the exact same procedures, including receiving muscle relaxants, being anaesthetized, having the electrodes placed on the head, and so on. The only difference is that in the sham ECT group no electric shock is given. To make the study double blind, neither the subjects nor the attending ECT team nor the subsequent raters of the subjects' condition are supposed to know to which group the subjects have been assigned. The results of the two groups are then compared to see if there is any difference.

Although the attempt to control for a placebo effect might work well when testing drugs - it is next to impossible to know if one has dispensed or received a placebo or a real drug-there are inherent problems in applying this procedure to ECT trials. For not only is it obvious that those administering the ECT will be able to tell whether a real shock has been given (especially if EEG monitoring is in place), there will also be a clear difference in the recovery situations of the two groups of persons: the real ECT group will tend to wake up with sore muscles, pounding headaches, confusion, nausea, loss of memory, and fear; the sham ECT group will not. This is an immense and uncontrolled for difference between the two groups. It might be thought that any bias effects of this difference could be overcome by using independent blind raters rather than allowing the subjects to rate themselves. But this safeguard fails for at least two reasons. First, if the recipient of a sham ECT treatment had read about or discussed the effects of ECT with others who had previously received (real) ECT, or had been properly warned about the side effects of (real) ECT before consenting to take part in the study-and it seems that because of ethical considerations he or she would have received such waming - then it is likely that the person would marvel over the fact that none of the headaches, memory loss, and so on, had happened to him or her. Further, if the person knew that there was a possibility that he or she might receive sham ECT, then it is fairly obvious that the person would have little trouble guessing that he had received the sham ECT. This awareness will exist and thus have likely effects on the person's subsequent behaviour whether or not an independent rater is used. Secondly, it is likely that the independent rater himself or herself will also be able to detect whether a subject underwent the post-ECT symptoms of headaches, confusion, and so on, and thus whether they had real or sham ECT. If this were the case, then there would exist a clear possibility for experimental bias. All of this raises a large question mark over the validity of studies that compare real and sham ECT.

In addition to these problems there is much inconsistency in the real versus sham ECT findings. For although some researchers claim that real EGT has a marked advantage over sham ECT, others have found that any apparent advantage of real ECT over sham ECT begins to disappear between one and six 
months later (Johnstone et al., 1980; Gangadhar et al., 1982; Brandon et al., 1984, See also Johnstone and Crow's (1985) review). In one tightly controlled doubleblind study Lambourn and Gill (1978) administered real ECT and sham ECT to two randomly assigned groups of 16 psychotically depressed persons. It was found that both groups showed a marked improvement, with the real ECT group showing more improvement on only one item out of a scale of 16 itemswhich, as Lambourn and Gill say, could easily have occurred by chance alone, or, I might add, by the differences in the recovery situations of the two groups. "The implication of these findings," they conclude, "is that the effectiveness of unilateral brief pulse ECT [the type they employed] shown in previous investigations is due in large part to the attendant procedures associated with the administration of an anaesthetic and the mystique associated with an unusual form of treatment" (Lambourn and Gill, 1978, p. 519) (It is worth noting here that brief pulse ECT is thought by other researchers to be more efficient than the other sine wave version of ECT (Abrams, 1991; Sackeim et al., 1986).) This negative conclusion concerning ECT's effectiveness is well expressed by Pinel in his comments on Weiner's (1984) long, exhaustive, and overall positive review of the literature. Pinel's conclusion is "in view of the many studies of ECT that have accumulated since its introduction, it is disconcerting that there is still little convincing evidence that ECT is of long-term value" (Pinel, 1984, p. 30). (Pinel's reaction to Weiner's review is concurred with by Breggin (1984). For more enthusiastic responses to Weiner's review and further attempts to defend ECT see Fink (1984) and Price (1984)).

Here, I feel, we get an answer to a commonly voiced defence for the use of ECT. There are ECT advocates who admit the cognitive damage, memory loss, and other complications associated with ECT. They reply, however, that such side effects are acceptable because they are outweighed by the benefits of overcoming a deep depression. The problem, however, is that, as just shown, it is unclear that ECT enables a person to overcome his depression in any important way. However, as we have also seen, there is good evidence that ECT causes both temporary and long-term cognitive damage. Consequently, all that is achieved by giving someone real ECT is to give him cognitive damage. Thus the depressed or psychotic ECT recipient has not only his continuing depression or psychosis to struggle with but, on top of that, now has to struggle with the cognitive damage from ECT. It might be true that someone's striking your finger with a hammer makes you temporarily forget about your toothache, but later not only will your toothache still be there, you will also have a broken finger.

\section{MOTIVATION BEHIND THE USE OF ECT}

In spite of all this, the use of ECT continues. In the words of one group of researchers, "whatever the reason for the lack of outstanding results in recent 
controlled trials, ECT is firmly established as an important treatment modality in psychiatry" (Small, et al., 1986, p. 1005). But there is something inherently odd about this statement. For in saying "whatever the reason for the lack of outstanding results in recent controlled trials", Small and his co-workers seem to be implying that ECT should have outstanding results but for some unknown reason it does not. But there is no reason-neither theoretical nor empirical-to think that ECT should have outstanding results. Consequently, the best explanation for ECT's lack of outstanding results in controlled trials is the same explanation we would give to any other treatment which failed to show outstanding results in controlled trials, namely, that the treatment is ineffective. If, in discussing his trade, a blood-letting practitioner were to say to us "whatever the reason for the lack of outstanding results in recent controlled trials...", a natural response would be to interject that there is no reason for blood-letting's lack of outstanding results other than that it is simply ineffective-letting blood has nothing to do with healing--not to mention that it lacks a theoretical basis and is, on top of all that, dangerous. The real mystery, then, is why ECT is "firmly established as an important treatment modality in psychiatry". For how is it that an ineffectual treatment could become important and firmly established? Plainly not because of its effectiveness. Could it be then that there are other hidden reasons which are driving the use of ECT? The suggestion that the motivation for the use of ECT has little to do with its supposed therapeutic value is not a new one. Reflecting on both the lack of empirical evidence behind ECT and its serious side effects, Giamartino (1974) suggested that psychiatrists might well have "ulterior motives" for employing ECT. He does not, however, attempt to explore fully the question of what such motives might consist of, suggesting only that they might involve the need to give an "illusion of treatment" by whatever means possible. This, however, does not explain why the illusion of treatment that is ECT is used instead of other possible of illusory treatments, especially when the serious side effects of ECT are taken into account. But what, then, could these ulterior motives be? The answer, I want to suggest, has to do with a set of features which are intimately associated with and easily discernible in the practice of ECT. These are the features of dehumanization, power, control, and various other related themes, all of which can be traced back to the fear of deviance. Giamartino is himself aware of the associated feature of dehumanization-though he does not consider it as an ulterior motive-claiming that ECT "is one, if not the most dehumanizing treatments to which a patient may be subjected" (1974, p. 1130). It is important to see, however, that the fact that ECT might have these associations is not meant to be taken as an argument against the use of ECT. Such an argument is found by looking to the lack of theoretical basis, the dangers, and poor results of ECT. The question that is now being asked concerns the motizes behind the use of ECT, a use which persists in spite of these inherent problems. It is by way of answering this question that I now turn to these features of ECT. 
An awareness of such features can often be discovered as a minimally voiced subtext in the literature on ECT. Thus, Fink assures us that "above all, we believe that a greater understanding of this effective therapy will increase our knowledge of severe mental disorders, perhaps to the degree that will permit this therapy to be replaced by one that is more elegant and more acceptable" (1985, p. 2). This remark is interesting not only because it reveals an awareness that the effectiveness of ECT is enough in question that in order to advocate its use one had better refer to it as "this effective therapy", rather than simply as "this therapy", but also, because it shows an awareness that ECT is somehow inelegant and unacceptable, though exactly what he means by this is left unsaid. Likewise, Squire (1987) refers to the "benign character of contemporary ECT practice", implying that there might have been something malignant about carlier ECT practice, and even that people might still see it as a malignant practice--which is why we have to be told that it is benign. Also, in Lickey and Gordon's attempt to defend the use of ECT they conclude by saying "most people are offended by the idea of sending large jolts of electric current through the brain. Frankly, so are we" (1991, p. 208). But they then go on to reassert their belief in its effectiveness. This, however, is an interesting admission: namely, an admission by those who advocate ECT that they find it offensive. But why, one wants to ask, do Lickey and Gordon find ECT offensive? Although they do not say, one likely answer seems to be that, as Giamartino (1974) suggests, it is obviously dehumanizing (which is also why one might find it inelegant or malignant). That is, to take a person and send a large jolt of electric current through his or her brain is to treat the person as if he or she were a machine. For in our daily lives electricity is something which we normally employ with machines and electrical appliances: we switch on the light, start the microwave, push down the toaster, and start the car, all with electricity. Thus in sending a jolt of electricity from a machine through a person's brain - the organ of human awareness and personality-it is difficult not to notice the subtle implication that the person has been reduced to something like an electrical machine. Images of artificial persons and robots also come to mind.

One might be tempted to object here that electricity is also used in other applications to the human body, such as in cardiac resuscitation in the case of heart failure, and that if the jolts of electricity are dehumanizing when given in ECT, then they are also dehumanizing when given in these other cases. But this, it might be continued, is absurd. But why is it absurd? It is absurd because an electrical application like that used in cardiac resuscitation is clearly a life-saving technology. Consequently, any dehumanizing aspects of it are overridden by the fact that it directly causes human life to continue. The expected reply here, one which has been made by various ECT advocates (such as Lickey and Gordon, 1991), is that ECT also enables human life to continue: it does so by preventing suicide. The problem with this, however, is that the data do not support such a claim. For there is much inconsistency in the research with several studies finding 
no difference in the suicide rates of depressed persons who had received ECT and those who had not (for example, Avery and Winokur, 1976; Babigian and Guttmacher, 1984; Black et al., 1989). In one large study which followed 1,494 hospitalized psychiatric patients for between five and seven years it was found those who had received ECT were even more likely to commit suicide than those who had not, though this difference was not statistically significant. "These findings," conclude the authors, "combined with a close examination of the literature do not support the commonly held belief that ECT exerts long-range protective effects against suicide" (Milstein et al, 1986, p. 3). ECT is therefore not a life-saving treatment, and may even be the reverse.

A further problem involved in attempting to equate ECT with electrical cardiac resuscitation is that the electricity in the latter case is not being applied in such a way that it damages the person's mental functioning. Part of the dehumanizing aspect of ECT here is that the electric shock is aimed straight at the core of the person's humanity, namely the person's intellectual abilities, memory, and other cognitive functions, and can severely compromise those abilities.

This dehumanization is further underscored by the immediate result of the electric shock, namely, the violent convulsions of the seizure. Here the person's control over his own bodily movements disappear, and free, intentional movements are suddenly replaced by mechanical-like contortions of the body. Here the body loses its human dimension and becomes a mere physical object reacting to the laws of physics. In his discussion of the body, Sartre (1943) argues that it is just such non-intentional movements of the body - the quivering or wobbling of the flesh-that are often seen as obscene or offensive. Of course, as mentioned, ECT now tends (though not always) to include the use of anaesthesia and muscle relaxants. But this was necessitated by the violent nature of the contractions. The obvious dangers involved in these contractions meant that unless the dangers were somehow avoided, the practice of ECT would have been even more called into question than it already was: it was, at least by Western standards, an act of necessity for those who wanted to keep using ECT. But ECT was invented and enthusiastically pursued long before it was used with anaesthetics and muscle relaxants. It should also be noted that the use of these drugs does not always remove the contractions, rather they serve only to dampen them.

Further, the fact that memory loss is an effect of ECT also accentuates the dehumanization of the procedure. Many philosophers argue that memory is the very basis of personal identity (see Perry, 1975). If this is true, then it follows that ECT's damaging of a person's memory is more or less a damaging of the person's identity. However, even without taking a stand on the relation of memory to personal identity, it is still obvious that memory is a central factor in connecting a person's present awareness to his or her past and establishing a person's sense of continuity. This sense of continuity is one of the things which serves to 
distinguish us from non-human things. For even though trees and stones, like human beings, have a past, they have neither an ability to have an awareness of their past nor a sense of continuity over time. Consequently, to damage a person's memory seems to be equivalent to sending the person in the direction of becoming a non-human thing, that is, to damaging one of her human abilities. A person with a damaged memory is often felt to be missing part of what it is that makes him or her fully human. For example, it is not uncommon to hear it said of a senile person with memory loss that she has "lost her mind". And it is hard to see someone as being fully human if we feel she has lost her mind.

As a procedure which delivers electric shocks, ECT also has strong associations with power and control. In many prisons electrified fences, which deliver powerful shocks, are used to control the movements of prisoners. Similar fences are also used to control the movements of livestock and other animals, while in slaughterhouses electrical shocks are often used to stun the animals before they are killed. Electric shock is also used in the case of "stun belts" worn in some places by prisoners working outdoors. Here, a guard can use remote control to deliver a powerful and disabling electric shock to a misbehaving prisoner. The association here of electric shock to power and control is underscored by the fact those being subjected to such shocks are usually, like psychiatric patients, also a type of social deviant, namely, criminals. The immediate effects of ECT also dramatically express the feature of power and control. For in applying an electric shock to the recipient's brain the ECT practitioner demonstrates his power and the recipient's helplessncss. The ECT practitioner's power is clearly expressed in his control over the recipient's bodily movements: he can cause the recipient's body to jump and contort by the mere flick of a switch. There is much here that fits with Foucault's (1978) analysis of how medical practitioners entrench themselves in a position of superiority over others by employing various techniques to maintain and extend their social power and control. Using ECT clearly ensconces its practitioner in such a position: the ECT recipient becomes like a puppet on a string which the ECT practitioner, with the ease of a puppeteer, causes to dance. The difference is that whereas practices like autopsies and naked examinations - practices that Foucault says establish the power of physicians by allowing them to break taboos - also have the effect, or at least can have the effect, of advancing medical practice and health, EGT does not. Further, autopsies and naked examinations were not developed with the idea of being performed on psychologically deviant persons: ECT was. It is this latter point, that the ECT candidate is seen as a deviant, that suggests, as we shall see shortly, the connection between power and control and something one fears.

There are also interesting parallels here with ritual exorcism and ECT. In Punjabi Muslim exorcism, for example, the psychologically deviant person is seen to be possessed by a jinn or demon. The person is brought to a Pir or exorcist who, after performing various preparatory rituals, then takes a stick and gives the patient a severe beating (Ewing, 1984). This beating is purportedly an 
attempt to induce the demon to leave the patient. However, since beating someone with a stick has obvious associations to power and control, it can also clearly be seen as an expression of the desire for power and control over the deviant person himself. Similarly, in modern Western culture the deviant person is seen to be possessed by "mental illness". Here the person is brought to a psychiatrist who, also after performing various preparatory rituals (for example, holding a diagnostic interview, administering the Hamilton Rating Scale for Depression, and so on) then takes an ECT machine and gives the patient a severe electric shock. As in the case of the beating administered by the exorcist, this shock administered by the psychiatrist is purportedly an attempt to induce the deviancy-here characterized as "mental illness" rather than as a demon-to leave the patient. However, since being given an electric shock has strong associations to power and control, it too can clearly be seen as an expression of the desire for power and control over the deviant person himself.

A natural response to a psychologically impairing, dehumanizing, and controlling procedure is one of fear. From the early days of ECT it has been known that the majority of persons undergoing ECT have such fears (Gallinek, 1956). It is worth noting therefore that despite the fact that it is eminently understandable that a person should have this fear, some ECT advocates, like Fox (1993), have nevertheless tried to argue that ECT recipients' fears are "pathological". Since it is fairly obvious why anyone would fear ECT, it seems likely that the attempt to stigmatize such fears as "pathological" is but one more way of labelling the ECT recipient as deviant and thus trying to justify the use of ECT.

It is easy to dismiss any one of the features of dehumanization, power, and control as being merely an accidental feature of ECT practice: an inelegant, malignant, or offensive feature which is merely incidental to the use of ECT and has nothing to do with the motives behind its use. But when one finds many such features, all with obvious and intimate associations to the practice of ECT, it then begins to look less and less likely that they are mercly incidental to its use. That these features play a central role in the use of ECT is further supported by the fact that ECT is ineffective, has no sound theoretical basis, is plagued with serious side effects, and thus has no therapeutic reasons to justify its use. For with little therapeutic or theoretical features to recommend it, and with damaging side effects to recommend against it, what is left to ECT other than its coercive features?

\section{THE FEAR OF DEVIANCE}

But how is it that the features surrounding the use of ECT might be implicated as a motive for its use? In other words, what would the reason be for wanting to dehumanize, have power over, or control the person who is selected for ECT? The answer, it seems, is found by looking to what sort of person is chosen to 
undergo ECT and by examining the way in which we typically respond to such a person. It has been well known for some time that psychologically deviant persons are a source of discomfort and fear for other people (Nunnally, 1960). It is thus no accident, I would argue, that the first subject for ECT was a deviant vagrant who was speaking "incomprehensible gibberish" and had no apparent knowledge of his identity. Such an individual poses a threat to our cultural values and the firmness of our own grasp on reality, especially when he is wandering the streets rather than being confined in an institution. Schizophrenia, as mentioned earlier, is characterized by hallucinations, delusions, selfneglect, and a loss of contact with what others considered reality. The so-called schizophrenic person claims to hear things we do not hear; he believes himself to be someone who we do not believe him to be; he either does not notice or does not care that his shoes have worn out at the bottom, that his clothes and body are filthy and hair matted. Consequently, he is perceived as deviant, and his deviance is something that threatens both our cultural values and our view of reality. He threatens our cultural values because he does not seem to notice or care what others think about his behaviour or appearance, or care about himself in the way that our culture feels he should. Such behaviour cannot help but raise the question of whether the things which we value are really valuable.

Further, he threatens our view of reality because although he seems to be hearing voices and is clearly engrossed in what he thinks they are saying, I myself can hear no voices and therefore believe, or at least want to believe, that in reality there are no voices. I therefore explain the difference between his situation and mine by saying that while I have a firm contact with reality and am sane, he has lost such contact and is mad. But how can I be sure that it is not I who am mad? Of course I have a strong conviction that my view of reality is the correct one, but then he has a strong conviction that he is hearing real voices. I can of course attempt to confirm that my view of reality is the correct one by mustering the consensual validation of those around me: people will clearly agree with me that there are no voices to be heard. And yet, how do I know that the people whose voices I hear validating my view of reality are not themselves merely elements in my own hallucination, much on the same level with the voices that the so-called schizophrenic person claims to hear? These are unsettling questions to which there is no obvious answer, questions which philosophers have struggled with at least since the time of the ancient Indian philosopher Dharmakirti (see his Samtānantara-siddhi in Wood, 1991). Fortunately, in our daily lives these questions are barely raised. But when we come into contact with such a person, it is much more difficult to ignore such disturbing issues.

And similar things could be said about the conditions of mania and severe depression. For the person undergoing mania, who is wildly euphoric over something which we find uninteresting or unimportant, tempts us to question our own views about what it is worth being excited over and what has value, while the severely depressed person, who sees the future as black, sees no point in 
living, and contemplates suicide, calls our own contentment into question, or even awakens similar but well-hidden feelings in us. Camus (1942), for example, argues that "there is only one really serious philosophical problem, and that is suicide". The inherent absurdity and pointlessness of existence, says Camus, is continually calling upon each of us to find a reason not to commit suicide. Such ideas can be frightening, and it is understandable that most people would rather not think too deeply about them (for what if one can not find such a reason?). And yet the very presence of someone in the darkness of depression kindles our fear by tempting us to question the value of our own existence.

One way of dealing with the threat that such deviancy poses is actively to avoid or put a distance between oneself and persons displaying such deviance. This is the way that most people respond to those posing other threats, such as those stigmatized with physical defects (see Rumsey et al., 1982) and it is probably the way that most people respond to the threat posed by a psychotic person. Plainly, close contact with such a person is discomforting, and putting a good distance between oneself and the person is a simple way of reducing the anxiety he or she arouses in us. However, although this may be a suitable response for the ordinary person who has no obvious obligations towards psychotic individuals, it is not a suitable response for the psychiatrist (which is not to say that psychiatrists do not, in their own way, attempt to avoid such persons). Here, the nature of the psychiatrist's profession requires that he or she deals more directly with the person in a manner that can at least be construed as a way of helping the person. But there is no reason to think that the fears which the psychotic person arouses in the ordinary person are any greater than those which they arouse in the psychiatrist. Sinanoglou (1987), for example, argues that those working in psychiatric settings are influenced by basic fears which are provoked by close contact with psychotic patients. This much would follow from Lucas and Barrett's (1995) view that "primitivism is one of the principal means of understanding mental illness in Western psychiatry. Madness is construed as the upsurge of the primitive within us." Consequently, "the impulses which are released in this regressed state are themselves characterized as primordial, dangerous and disordering" (1995, p. 314). If this view is right, then at the very heart of Western psychiatry lies a conception of madness which sees it as being dangerous. Although Lucas and Barrett do not say why such apparently primitive impulses should be seen as dangerous and disordering, the answer, I would argue, is because, as shown earlier, they threaten our view of reality and our values.

One response which is open to the psychiatrist here, a response which deals directly with the psychotic person while at the same addressing the threat he poses, is to treat him in a dehumanizing way. For in treating him thus his similarity to oneself is weakened. What is frightening about a psychotic person is that although he is human like myself, he nevertheless has views of reality and values that are fully at odds with mine. By treating him in a dehumanizing way 
I can attempt to convince myself that he is not fully human and therefore not fully like myself. This helps to defuse the anxiety that I experience over the threat he poses to my world view because now his views are seen to be those of someone who is less than human. Such a person's views are not felt to compete viably with my own. Consequently, I need not take them seriously and the seeming validity of my own conceptions, along with my sense of security, are preserved.

That psychiatric patients are subject to dehumanizing treatment is well documented. At the end of the 18th century Benjamin Rush, known as the father of American psychiatry, advocated locking psychiatric patients in coffin-like boxes and immersing them in water. Later, in the 19th century small crib-like cages were used to restrict any movement. More recently, it has been shown that psychiatric patients routinely receive verbal, physical, and psychological, abuse from those working in psychiatric institutions. In Rosenhan's (1973) well-known study confederates admitted themselves to psychiatric hospitals pretending that they were hearing voices. While in the psychiatric hospital they were able to observe the way in which the psychiatric staff treated the patients. In one case the morning attendant would often wake the patients with "Come on, you $\mathrm{m}$ f - $s$, out of bed!". In another case a patient was beaten in the presence of other patients merely because he had said to an attendant "I like you". "Occasionally", says Rosenhan, "punishment meted out to patients for misdemeanors seemed so excessive that it could not be justified by the most radical interpretations of psychiatric canon" (1973, p. 256). Also, practices like denying patients the right to send or receive post or to use the telephone, opening their letters, denying them the right to have visitors or access to outdoors, strip searches, forced baths, threats of reprisal for any complaints, and so on, seem the daily fare in many psychiatric institutions (Andersen and Collingnon, 2000a). Dehumanization here can also take subtler forms. In one telling example from Rosenhan's study, a female psychiatric nurse who was in full view of an entire ward of male patients, unbuttoned her blouse and adjusted her brassiere. There was no sense that she was trying to be sexually arousing, rather she simply had no awareness of the men who were watching her. Since it is unlikely that this nurse would similarly open her blouse and play with her brassiere while at a case conference with her male colleagues, or even at any other public place where men were viewing her, one immediately wonders why she feels she can do so with the men watching her here. The likely answer is that since she sees the men here as psychological deviants she has dehumanized them to the point where she does not even think of them as men who might have sexual awareness. Thus, she need not have the same concern about exposing her underclothing to them as she would to other men.

With all of this the attractiveness of ECT as a psychiatric treatment now becomes discernible. For ECT not only appears to be therapeutic treatment but, as shown earlier, also dehumanizes the deviant person by seeming to reduce him 
to an electrical machine. Further, it not only dehumanizes him but, as also shown earlier, it gives the ECT practitioner a sense of power and control over the recipient. For by throwing his body into contortions, erasing his memories, and by inducing confusion and fear, the ECT practitioner shows his power by demonstrating the ease with which he can control the deviant person's movements and thought processes. A person who can be controlled so easily is not one whom the ECT practitioner needs to be fearful of. When all of this is considered in the light of the fact that there are no good therapeutic reasons for using EGT, and many compelling reasons not to use it, then the conclusion which suggests itself is that it is just these features which are the motivating force behind the persistent use of ECT.

There are, of course, other ways of dealing with psychotic people, such as giving them antipsychotic or antidepressant drugs. But such drugs lack the use of an electrical machine, electricity through the brain, loss of memory, muscular convulsions, and so on. In other words, they lack the same ability to dehumanize, to give instant control, or to render an instant feeling of power-which is not to say that drugs do not do some of these things in another way. Long-term use of antipsychotics like chlorpromazine and haloperidol can result, for example, in tardive dyskinaesia, an irreversible disorder in which various bodily movements become uncontrollable, repetitive, and grotesque. This condition, however, which affects about 25 percent of patients using such drugs, takes many years to develop (Lickey and Gordon, 1991) and lacks the dramatic and instantaneous convulsions and cognitive damage attendant on ECT. A further option would be prefrontal lobotomy, another dehumanizing treatment which in its heyday was, suggestively enough, frequently used in conjunction with ECT. The problem here, however, is that the effects of psychosurgical procedures like prefrontal lobotomy usually proved so devastating - here the psychological impaiment and brain damage, which was the essence of the procedure, could not be denied or even downplayed - that even its most devoted advocates were eventually unable to convince others of its usefulness. Consequently, prefrontal lobotomies are no longer a viable option in the attempt to dehumanize or have power and control over the deviant. One, however, must be cautious in making such statements since a more recent type of psychosurgery, cingulotomy-a procedure whose effects some critics have likened to those of lobotomy is still in use (Scott, 2000).

None of this is to say that the features mentioned are the only ones which determine the use of ECT, for, like any practice, ECT is something which takes place in a complex web of historical and cultural factors. One such factor might be the central role that electricity holds in the history of science. As mentioned earlier, during the latter half of the 18 th century and into the early 19 th century there was much fascination with electricity as a mysterious force of nature. Various people then attempted to employ electricity as a curative agent. Some such residual fascination with the "mysterious" powers of electrical phenomena 
might well play a role in the continued attempts to deploy ECT. Indeed, EGT can easily be seen as a legacy of this early modern belief that life can be transformed through the mysterious powers of electricity.

In addition, there are also various incidental factors which, from time to time are implicated in the use of ECT. In Denmark, for example, it was recently discovered that one feature which played a role in determining whether a person received ECT was the person's postal code (Andersen and Collignon, 2000b). Here, for administrative reasons, psychiatric patients with certain postal codes were the ones who were admitted to the ECT ward. These patients were thus more likely to be given ECT. Also, it was found in a psychiatric hospital in Canada that the number of ECT sessions with geriatric patients nearly doubled - from 698 in 1996-97 to 1,249 in 1997-98 - after psychiatrists started receiving an extra $\$ 62$ per session from the provincial health-care plan (Mickleburgh, 2000). That factors like these play a role in the use of ECT should cast even further doubt over the view that the decision to use ECT has much to do with therapeutic considerations, and especially over claims that ECT is used only as a last resort when other treatments have failed. It seems unlikely, however, that such factors can go the full way to explaining the persistent use of a treatment whose lack of effectiveness, absence of a theoretical basis, and serious side effects qualify it for the title of the blood-letting of our time.

James Giles

Madingley Hall

University of Cambridge

Madingley

Cambridge CB3 $8 A Q$

United Kingdom

Acknowledgements: A version of this paper was presented at the Eighth East-West Philosophers' Conference "Technology and Human Values on the Edge of the Third Millennium", University of Hawaii, 2000. I should like to thank Charles W. Smith for his kind help and interest, and also the journal's referees for their useful comments.

\section{NOTE}

That dehumanization of deviant persons was also a major motive in the use of lobotomy is suggested by the actions of Walter Freeman, the principle American advocate of the procedure: "Following a round of electroconvulsive therapy, he took an ice pick and shoved it just above the eye under the lid, where the skull is paper thin, into the frontal lobes. He didn't even administer an anaesthetic". When criticized for employing 
an operation which permanently destroyed mental functioning, Freeman replied "Even if a patient is no longer able to write poetry or compose music, he is on the other hand no longer ashamed to fetch and carry, to wait on tables or make beds or empty cans" (Scott, 2000 , p. 86.

\section{REFERENCES}

Abrams, R., Swartz, C.M, and Vedak, C. (1991). Antidepressive effects of high-dose right unilateral electroconvulsive therapy. General Archives of Psychiatry, 48, 746-8.

American pSychiatric assoclation, (1990). The practice of electroconoulsize therapy: recommendations for treatment, training, and privileging. Washington, DG; APA.

AMERIGAN FSYCHIATrRe Associatron. (1994). Dhagnostic and statistizal mantul of mental disorders (4th edn) (DSM IV). Washington, DC: APA.

Andersen, S. and Collignon, P. (2000a). Den usynlige tyang i psykiatrien. Zyllands-Posten, 24 May, section $1,10$.

Axdersen, S. and Collignon, P. (2000b). Elektorchock afgøres af postnummer. FyllandsPosten, 28 May, section 1, 1 .

Andersen, S. and Collignon, P. (2001). Jeg glemte alt; Mirakelkurens bagside fyllandsPosten, 25 March, Indblik, 1, 2.

ANDERsen, N.C., ERnhardT, J.G., SwaYzE, V.W., et al. (1990). Magnetic resonance imaging of the brain in schizophrenia. Archives of General Psychiatwy, 47, 35-44.

Auerbach, J.S. and BLATt S.J. (1997). Impairment of self-representation in schizophrenia: The roles of boundary articulation and self-reflexivity. Bulletin of the Menninger Clinic, $61,3,297-316$.

AVERY, D. and Wrokur, G. (1976). Mortality in depressed patients treated with electroconvulsive therapy and antidepressives. Archives of General Psychiatry, 33, 1029-1037.

BabigIAN, H., and GutTERmacher, L. (1984), Epidemological consideration in electroconvulsive therapy, Archives of General Psychiatry, 41, 246-253.

BarTon, J.L. (1977), ECT in depression: The evidence of controlled studies. Biological Psychiatry, 12, 687-695.

Brack, D., Wryokur, G., Mohandoss, F., at al. (1989). Does treatment influence mortality in depressives? A follow-up of 1076 patients with major affective disorder. Annals of Cinical Psychatin, 1, 165-173.

BLAvok, P.D. (1993). (ed), Interpersonal Expectations: Theory, Research, and Applications, Cambridge: Cambridge University Press.

Bond, M. (1985). The psychiatry of closed head injury. In N. Brooks (ed), Closed Head Inyury: Psychological, Social, and Family Consequences. Oxford: Oxford University Press, pp. $148-178$.

Brandon, S.P., Gowley, P., Mcdonald, C., et al. (1984). Electroconvulsive therapy: Results in depressive illness in the Leicestershire trial. British Medical Joumal, 288 , $22-25$.

Bregcrn, P.R. (1979). Electroshock: Its Brain-Disabling Function. New York: Springer.

BregGIN, P.R. (1984). Electroshock therapy and brain damage: The acute organic brain syndrome as treatment. The Behavioral and Brain Sciences, 7, 1, 24-25.

Bregon, P.R. (1997). Brain Disabling Treatments in Psychiaty: Drugs, Electroshock, and the Role of the FDA. New York: Springer.

Brierre DE BoIsMon, A.J.F. (1859). The treatment of hallucinations. R.T. Hulme (trans.). In R. Hunter and I. Macalpine (eds), Three Hundred Tears of Psychiatry. London: Oxford University Press (1970), pp. 1058-1062. 
Brooks, N. (1985). Cognitive deficits after head injury. In N. Brooks (ed), Closed Head Injury: Psychological, Social, and Fomily Consequences. Oxford: Oxford University Press, pp. 123-147.

Galev, A., Drexe.er, H., Tubr, N., at al. (1991). Atropine and cognitive performance after electroconvulsive therapy. Convulstive Therapy, 7, 92-98.

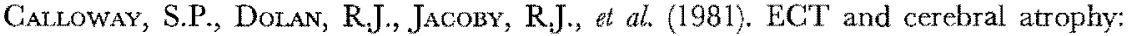
A computed tomographic study. Acta Psychiatrica Scandinarica, 64, 442-445.

Camus, A. (1942). The Myth of Sisyphus. J. O'Brien (trans.), London: Penguin (1975).

Cerlettr, U. and Bint, L. (1938). L'elletroshock. Archives of General Nourology and Psychiatry, 19, 266-268.

Cminders, R,T, (1964). Comparison of four regimens in newly admitted female schizophrenics. American Joumal of Psychiatry, 129, 1010-1011.

COFFEy, C.E., WEInER, R.D., DJANG, W.T., et al. (1991). Brain anatomic effects of electroconvulsive therapy: A prospective magnetic resonance imaging study. Archives of General Psychiatry, 48, 1013-1021.

Corsellis, J.A.N. and Meyer, A. (1954). Histological changes in the brain after uncomplicated electro-convulsive treatment. Foumal of Mental Science, 100, 375- 383.

Corseluis, J.A.N. and Brutox, C.J. (1983). Neuropathology of status epilepticus in humans, Advanced Neurology, 34, 129-139.

DanIel, W.F. and CRovitz, H.F. (1983). Acute memory impairment following electroconvulsive therapy: 2. Acta Psychiatrica Scandinatica, 67, 57-68.

D'ELIA, G, and RAOTMA, H. (1975). Is unilateral ECT less effective than bilateral EGT? British Joumal of Pychiatry, $126,83-89$.

Devanand, D.P., Dwork, A.J., Hutchinson, E.R., et al. (1994). Does ECT alter brain structure?, American foumal of Psychiatry, $151,7,957970$.

EwING, K. (1984). The sufi as saint, curer, and exorcist in modern Pakistan. In E.V. Daniel and J.F. Pugh (eds), South Asian Systems of Healing, vol 18. Contributions to Asian Studies, Leiden: EJ, Brill, pp. $100-114$.

FELDMAN, R.S. (1997). Essentials of Understanding Psychology (3rd edn), New York: McGow-Hill.

Fink, M. (1984). EGT-verdict: Not guilty. The Behawioral and Brain Seiences, 7, 1, 26-27.

FINk, M. (1985). Editorial: Convulsive therapy. Contulsive Therapy, 1, 1, 1-3.

FInK, M. (1993). Who should get ECT? In C.E. Coffey (ed.), The Chinical Science of Electrom conenlsive Therapy. Washington, DG: American Psychiatric Press, pp. 11-19.

Foucault, M. (1978). The Birth of the Cinic: The archeology of medical perception. A. Sheridan (trans.), New York: Random House.

Fox, H.A. (1993). Patients' fear of and objection to electroconvulsive therapy. Hospital and Community Psychiatry, 44, 4, 357-360.

Freeman, C.P.L., Weeks, D., and Kendatl, R.E. (1980). EGT: Patients who complain. British Journal of Psychiatry, 137, 17-25.

Friedbero, J. (1977). Shock treatment, brain damage, and memory loss: A neurological perspective. American Joumal of Psychiatry, 134, 9, 1010-1014.

FrtTh, C.D., Stevens, M., Johnstone, E.C., et al. (1983). Effects of ECT and depression on various aspects of memory. British fournal of Psychiatry, 142,610-617.

Gatlinek, A. (1956). Fear and anxiety in the course of electroshock therapy, American Joumal of Psychiatry, $113,428-434$.

Gavgadrar, B.N., Kapur, R.L., and Kalyanasundaram, S. (1982). Comparison of electroconvulsive therapy with imipramine in endogenous depression: A double-blind study, British Joumal of Psychiatry, 141, 367-371.

Gentleman's Magazine (1787). In R. Hunter and I. Macalpine (eds), Three Hundred Years of Psychiaty. London: Oxford University Press (1970), pp. 506-507. 
Giamartivo, G.A. (1974). Electroconvulsive therapy and the illusion of treatment. Psychological Reporis, 35, 1127-1131.

Goller, E.S. (1960). A controlled trial of reserpine in chronic schizophrenia. Joumal of Mental Science, 106, 1408-1414.

Gordon, H. (1948). Fifty shock therapy theories. Military Surgery, 103, 397-401.

Harres, M.J., (1991). Controversy and culmination: Meta-analysis and rescarch expectancy Effects. Personality and Social Psychology Bulletin, 17, 316-322.

HE, D. and LI, Z. (1985). Electroconvulsive therapy and acupuncture convulsive therapy in China, Conulsive Therapy, $1,4,234-241$.

HeycK, H. (1955). Uber einen Hirnbefund ohne ganglenzellausfalle nach 355 elektorkramfbehanlungen. Monatsschrift fitr Psychiatrie und Neurologie, 129, 128-137.

Inezue, H.U. and Exrobo (1981). Present status and practice of electroconvulsive therapy at the Psychiatric Hospital, Enugu, Nigeria. Acta Psychiatrica Scandinanica, 63, 325-332.

Impasato, D.J. (1960). The story of the first electroshock treatment. American Joumal of Psychiatry. 116, 1113-1114.

Janicak, P.G., Davis, J.M., Grebons, R.D., et al. (1985). Efficacy of ECT: A metaanalysis. American Joumal of Psychiatry, 142, 3, 297-302.

JANICAK, P.G., Sharma, R.P., ISRANi, T.H., et al. (1991). Effects of unilateral-nondominant vs. bilateral ECT on memory and depression: A preliminary report. Psychophamacology Bulletin, 27, 3, 353-357.

Johnstone, E.C, and Crow, T.J. (1986). Contolled trials of electroconvulsive therapy. In S. Malitz and H.A. Sackeim (eds), Electroconoulsine Therapy: Chintcal and Basic Research lssues. New York: New York Academy of Sciences, pp. 12-29.

Johnstone, E.C., Lawler, P., Stevens, M., et al. (1980). The Northwick Park electroconvulsive therapy trial. Lancet, $2,1317-1320$.

Julien, R.M. (1992). A Primer of Dng Action (6th ed) New York: W.H. Freeman.

Kfak, P., Mendlwicz, J., Calabrese, J.R. et al. (2000). A review of randomized, controlled clinical trials in acute mania. Joumal of Affective Disorders, 59, supplement 1 , $31-37$.

KING, P.D. (1960). Chlorpromazine and electroconvulsive therapy in the treatment of newly hospitalized schizophrenics. Foumal of Clinical and Experimental Psychopatholog, $21,101-105$.

LAMbourn, J. and Gir., D. (1978). A controlled comparison of simulated and real ECT. British fournal of Psychiatry, 133, 514-519.

Lancsley, D.G., Enterline, J.D., and Hickerson, G.X. (1959). A comparison of chlorpromazine and ECT in treatment of acute schizophrenic and manic reactions. Archizes of Neurology and Psychiairy, 81, 384-391.

Lawson, J.S., Inglis J., Delva N.J. et al. (1990). Electrode placement in ECT: Cognitive effects. Psychological Medicine, 20, 2, 335-344.

Lickey, M., and Gordon, B. (1991). Medicine and Mental Illness: The Use of Drugs in Pychiatry. New York: W.H. Freeman.

LIPPMANN, S. MANSHADT, M., WEHRY, M, at al. (1985). Electroconvulsive treatments without evidence of brain injury. British Joumal of Psychiatry, 147, 203-204.

LuCAs, R.H., and BARRETT R.J. (1995). Interpreting culture and psychopathology: Primitivist themes in cross-cultural debate. Caliure, Medicine and Pychiaty, 19, 287-326.

Madsen, T.M., Treschow, A, Bengzon, J., al. (2000). Increased neurogenesis in a model electroconvulsive therapy. Biological Psychiatry, 47, 12, 1043-1049.

Mckegnex, F.P. and Panzetta, A.F. (1963). An unusual fatal outcome of electroconvulsive therapy. American Joumal of Psychatry, 120, 398-400.

Meduna, L. J. (1937). Die kontulsionstherapie de schizophrenie. Halle, Germany: Carl Marhold. Meduna, L.J. (1985). Autobiography of L.J. Meduna, Part 1. Conulsive Therapy, 1, 43-57. 
Mickleburgh, R. (2000), B.C. to probe rise in ECT billing. The Globe and Mail, 10-15 December, section A, 9 .

Mitstein, V., Smat., J.G., Smat., I.F., et al. (1986). Does electroconvulsive therapy prevent suicide? Conoulsive Therapy, 2, 1, 3-6.

Munich, R.L. (1997). Contemporary treatment in schizophrenia. Bulletin of the Menninger Clinic, 61, 2, $189-221$.

NAmoo, D. (1956). The effects of reserpine (serpasil) on the chronic disturbed schizophrenic: A comparative study of rauwolfia alkaloids and electroconvulsive therapy. Joumal of Nenous and Mental Disorders, 123, 1-13.

Nunnaliy, J.G. (1960). Popular conceptions of mental health. New York: Holt, Rhinehart, and Winston.

ODEJTE, A.O. (1980). A study of the in-patient practice of a Nigerian psychiatric hospital. Comprehensive Psychialo, 21,4, 302-307.

Petrmatr, H.M. and Bonner, K.M. (1984). Cognitive functioning in depressed geriatric patients with a history of ECT. American Joumal of Psychiatry, 141, 49-52.

Perry, J. (Ed) (1975). Personal Identity. Berkeley, California: University of Califomia Press.

PINEL J.P.J. (1984). After forty-five years EGT is still controversial. The Behoworal and Brain Sriences, 7, 1, 30-31.

PRIGE, T.R.P. (1984). Modem EGT: Effective and safe. The Behazioral and Brain Sciences, 7, $1,31-32$.

Rosenhan, D.L. (1973). On being sane in insane places. Science, 179, 4070, 250-258.

Rudorfer, M.V. and Goodwin, F.K. (1993). Introduction. In C.E. Coffey (ed), The Clinical Science of Electroconzulszie Therap. Washington, DC: American Psychiatric Press, Pp. $21-29$.

Rumsey, N, Bull R., and Gahagen, D. (1982). The effect of facial disfiguration on the proxemic behavior of the general public. Foumal of Applied Social Psycholog, 12, 2, 137 150.

SAckerm, H.A. (1988). Mechanisms of action in electroconvulsive therapy. In A.J. Frances and R.E. Hales (eds), Annual Rentw of Psychiatry, vol. 7. Washington, DC: American Psychiatric Press, pp. $436-457$.

SAJU, P.J., and JACOB, K.S. (1993). ECT in schizophrenia: Need for reappraisal? British Joumal of Psychiatry, 162, 573-574.

SARTRE, J.-P. (1943). Being and nothingness: An essay in phenomenological ontology. Hazel E. Barnes (trans.), London: Methuen (1956).

Scotr, A.I.F. (1989). Which depressed patients will respond to electroconvulsive therapy? The search for biological predictors of recovery. British Joumal of Psychatry, 154, $8-17$.

Scotr, S. (2000). Piece of Mind. Elm Street, February/March, 83-91,

SHukt., G.D. (1981). Electroconvulsive therapy in a rural teaching general hospital in India. British 7oumal of Psychiatry, 139, 569-571.

Sinanoglou, I. (1987). Basic anxieties affecting psychiatric staff and their attitudes to psychotic patients. Psychoanalytic Psychotherapy, $3,1,27-37$.

Smat.L, J.G., KLApper, M.H., Kellams, et al. (1988). Electroconvulsive treatment compared with lithium in the management of manic states. Archives of General Psychiatry, 45, $8,727-732$.

Smati, J.G., Mrlstern, V., Krapper, M., et al. (1982). EGT combined with neuroleptics in the treatment of schizophrenia. Psychopharmacology Bulletin, 18, 1, 34-35.

Small, I.F., Small, J.G., and Milsten, V. (1986). Electroconvulsive therapy. In P.A. Berger and K.H. Brodie (eds), Amenican Handbook of Psychatry (2nd edn), vol. 8 . New York: Basic Books, pp. 999-1028. 
SMrrt, K.W., Surperts, W.R.P., GyNTHER, M.D., et al. (1967). ECT-chlorpromazine and chlorpromazine compared in the treatment of schizophrenia. Foumal of Nervous and Mental Disease, 144, 4, 284-290.

SQUIRE, L.R. (1977). ECT and memory loss. American Joumal of Psychiatry, 134, 997-1001.

Squire, L.R., Slater, P.C., and Mller, P.L. (1981). Retrograde amnesia following ECT: Long-term follow-up. Archives of General Psychiatry, 38, 89-95.

SQUtRE, L.R and SLATER, P.C. (1983). Electroconvulsive therapy and complaints of memory dysfunction: A prospective three-year follow-up study. British foumal of Psychiatry, 142, $1-8$.

SQuire, S. (1987). Shock therapy's return to respectability. New Fork Times Magazine, 22 November, 79-89.

Steif, B.L., S.ackem, H.A., Portnoy, S., et al. (1986). Effects of ECT on anterograde memory. Biological Psychiatry, 21, 10, 921-930.

Stephens, S.M., Petrinati, H.M., Greenberg, R.M. et al. (1993). Continuation and maintenance therapy with outpatient ECT. In C.E. Coffey (ed.), The Clinical Science of Electroconzalsize Therapy. Washington, DC: American Psychiatric Press, pp. 86-97.

TAYlor, P. and Flemivger, J.J. (1980). ECT for schizophrenia. Lancet, 1, 1380-1382.

VAFIA, N.S., DoongajI, D.R., and Jeste, D.V. (1974). Twenty-five years of psychiatry in a general hospital (in India). Indian Joumal of Psychiatry, 16, $221-228$.

VAIDYA, V.A., SIUClak, J.A., Du, F. et al. (1999). Hippocampal mossy fiber sprouting induced by chronic electroconvulsive seizures. Neuroscience, 89, 1, 157-166.

Van Zomeren, A.H., Brouwer, W.H., and Deelmay, B.G. (1985). Attention deficits: The riddles of selectivity, speed, and alertness. In N. Brooks (ed.), Closed Head Iniury: Psychological, Social, and Family Consequences. Oxford: Oxford University Press, pp. 123147.

Wetnberger, D.R., Fulfer Torrey, M.D., Andreas, N., et al. (1979). Lateral cerebral ventricle enlargement in chronic schizophrenia. Archives of General Psychiaty, 36, 735-739.

WEINER, R.D. (1984). Docs electroconvulsive therapy cause brain damage? The Behatroral and Brain Sciences, 7, 1, 7-53.

Weiner, R.D., Rogers, H.J., Davidson, J.R.T., at al. (1986). Effects of stimulus parameters on cognitive side effects. In S. Malitz and H.A. Sackeim (eds), Electroconvulsive Therapy: Cinital and Basic Research Issues. New York: New York Academy of Sciences, pp. 315-325.

WEINER, R.D. and KRYstal A.D. (1993). EEG monitoring of ECT seizures. In C.E. Coffey (ed), The Clinical Science of Electrocontulsive Therapy. Washington, DG: American Psychiatric Press, pp. 93-110.

WeInstein, E.A. (1996). Symbolic aspects of confabulation following brain injury: Influence of premorbid personality. Bulletin of the Menniger Clinit, 60, 3, 331-350.

Weuls. K. (1999). Depths of despair: A primer on depression. Six Part Series in This Moming Programme (cassette tape). Toronto: Canadian Broadcasting Corporation.

WESLEY, J. (1760). Electrical treatment, consultation with Dr Monro. In R. Hunter and I. Macalpine (eds), Three Hundred Years of Psychiatry. London: Oxford University Press (1970), pp. 420-424.

- Woon, T.E. (1991). Mind Only: A Philosophical and Doctrinal Analysis of the Viñanazada. Honolulu: University of Hawaii Press. 